\title{
Maria Neli Sobreira: história e memória da educação em Juazeiro do Norte ${ }^{1}$
}

\section{Maria Neli Sobreira: history and memory of education in Juazeiro do Norte}

\author{
Lia Machado Fiuza Fialho* \\ Zuleide Fernandes de Queiroz ${ }^{* *}$
}

\begin{abstract}
RESUMO
Maria Neli Sobreira, madre educadora, foi responsável pela alfabetização de crianças e assistência social (1946-2017) às famílias na cidade de Juazeiro do Norte, Ceará, em período marcado, predominantemente, pela atuação de professoras leigas no meio rural. Questionou-se, todavia, que formação educacional e atuação profissional foram desenvolvidas por Neli Sobreira para que se constituísse figura relevante na memória coletiva local. Objetivou-se compreender a formação educativa ensejada a Neli Sobreira, especialmente em sua atuação profissional, na interface com o contexto sócio-histórico, que fomentou o desenvolvimento educacional no interior do Ceará. Por meio de uma pesquisa amparada metodologicamente na história oral biográfica, constatou-se que Sobreira foi uma freira que não atuou apenas no campo religioso de Juazeiro, mas também foi pioneira na política, elegendo-se vereadora. $\mathrm{Na}$ atuação educacional, foi a primeira professora normalista com habilitação específica equiparada ao ensino superior; além de muito atuante na área da assistência social, galgando importante papel na educação de crianças e na luta pela garantia de direitos à população pobre no Cariri.

Palavras-chave: Maria Neli Sobreira. Biografia. Juazeiro do Norte. Educação.
\end{abstract}

1 Pesquisa financiada pelo Conselho Nacional de Desenvolvimento Científico e Tecnológico (CNPQ) - "Educação e educadores(as) no Ceará do século XX: práticas, leituras e representações". Parecer do CEP: 630.923/14.

* Universidade Estadual do Ceará. Centro de Educação. Programa de Pós-Graduação em Educação. Fortaleza, Ceará, Brasil. E-mail: lia.fialho@uece.br. https://orcid.org/0000-0003-03939892.

** Universidade Regional do Cariri. Mestrado Profissional em Educação. Crato, Ceará, Brasil. E-mail: zuleide.queiroz@urca.br. https://orcid.org/0000-0003-3174-4750. 


\begin{abstract}
Maria Neli Sobreira, Reverend Mother and educator, was responsible for the literacy of children and social assistance (1946-2017) to families in Juazeiro do Norte City, in Ceará, in a period marked, predominantly, by the work of lay teachers in rural areas. A question arose, however, as to the extent of the educational formation and professional performance she had developed in order to become a relevant persona in the local collective memory. The objective of this study was to understand Neli Sobreira's educational background and, especially, her professional performance, in the interface between it and the socio-historical context, which fostered educational development in the countryside of Ceará. From a research methodologically based in oral biographical history, we have found that she was a nun who did not only act in the religious field of Juazeiro do Norte; on the contrary, Neli Sobreira was a pioneer woman in politics as a city counselor. She also became the first teacher there with a specific qualification similar to higher education. She was also very active in the area of social assistance, playing an important role in the education of children and in the struggle to guarantee the rights of the poor in Cariri.
\end{abstract}

Keywords: Neli Sobreira. Biography. Juazeiro do Norte. Education of Women. Teaching.

\title{
Introdução
}

A História da Educação no Ceará é marcada pela criação de instituições educacionais sob a orientação de religiosos (QUEIROZ, 2008). Na região do Cariri $^{2}$, o início de experiências escolares emerge com a chegada de missionários, em especial do Padre Ibiapina, com seu protagonismo na criação e administração das Casas de Caridade: "Padre Ibiapina construiu casas de caridade nos quatro principais municípios do Vale - Crato, Barbalha, Milagres e Missão Velha." (DELLA CAVA, 2014, p. 68). Estas instituições foram relevantes para a proliferação de lugares de escrever, de contar e do aprendizado do catecismo; mais tarde elas constituíram o mosaico da história da educação de Juazeiro do Norte e dos municípios circunvizinhos no Cariri.

Com base nos preceitos e princípios cristãos, sob a égide do catolicismo, as instituições e as ações educacionais nelas desenvolvidas começaram a se consti-

2 A Região Metropolitana do Cariri está localizada no Sul do estado brasileiro do Ceará e emergiu conurbação entre os municípios de Juazeiro do Norte, Crato e Barbalha, popularmente conhecido como triângulo CRAJUBAR. 
tuir com caráter assistencial, oriundas das ações de caridade às famílias pobres e às crianças abandonadas, bem como à educação das meninas. Esse trabalho foi marcado pela presença das beatas ${ }^{3}$, coordenadas pelo Padre Ibiapina, que colaboraram no fomento, organização e disseminação da educação tradicional em todo o Nordeste no final do século XIX (MADEIRA, 2008).

As beatas, consideradas as primeiras professoras e religiosas do lugar, viviam para a fé, a caridade e a educação prestadas às famílias, especialmente às pobres, com crianças do sexo feminino. Essa irmandade de beatas era constituída por mulheres leigas, triadas do povoado (GOIANA, 2016), formadas pela Igreja, "que tomavam o hábito pela primeira vez" (DELLA CAVA, 2014, p. 81). No entanto, em geral, essas mulheres foram invisibilizadas pela historiografia oficial - que lançava luz apenas aos feitos dos homens de prestígio político ou eclesiásticos da região -, ainda que responsáveis pela educação local.

Em Juazeiro do Norte, esse cenário se estendeu até 1940, quando o protagonismo das beatas do Padre Ibiapina e do Padre Cícero cederam lugar à atuação dos projetos educacionais de congregações, a exemplo das Filhas de Santa Teresa, que objetivavam desenvolver educação formal e assistência social para crianças pobres em escolas mistas, sem o forte viés da conquista de fiéis. Foi neste cenário que se destacou a história de vida da madre Maria Neli Sobreira, objeto de estudo deste artigo, responsável pela educação de muitas das crianças do município no período de 1946 a 2017. Sobreira tinha formação específica para tal atuação na escola normal e no curso de aperfeiçoamento realizado em Recife-PE, em meio a um cenário educacional marcado pela atuação de professoras leigas no meio rural, sob o ideário da religiosidade e preservação da pureza das meninas.

Neli Sobreira, primeira professora normalista com habilitação equiparada ao ensino superior do município, mesmo demasiadamente conhecida pelos moradores da região, presente fortemente nas memórias educativas dos moradores de Juazeiro, não ganhou destaque na História da Educação local tampouco nacional, embora tenha contribuído fortemente para com a Educação na região do Cariri. Imortalizada apenas com a dominação de uma avenida no bairro de Limoeiro, o que atesta certa visibilidade. No entanto, não desvela ou preserva sua história e memória no cenário educacional para o qual tanto contribuiu com a atuação como professora, gestora, fundadora de instituições e coordenadora de inúmeros projetos; trajetória a ser delineada com esta pesquisa.

3 Beata é um construto utilizado para fazer referência às mulheres que faziam votos de castidade e se dedicavam à Igreja Católica, "moças que não conseguiam casar-se e sequer tinham dote necessário para acolhimento nos conventos. [...] Eram aquelas que, além de não possuir dote, não recebiam doação para manter-se nem tinham superioras para fazer vigília ou rigor de suas penitências.” (MADEIRA, 2008, p. 119). 
Questionou-se, sem embargo, que formação educacional recebeu e qual atuação profissional foi desenvolvida por Neli Sobreira no contexto socioeducacional de Juazeiro do Norte para que se constituísse figura relevante na memória coletiva? Objetivou-se compreender a formação educativa ensejada a Neli Sobreira e, especialmente, sua atuação profissional na interface com o contexto sócio-histórico que fomentou o desenvolvimento educacional no interior do Ceará, mais especificamente, na cidade de Juazeiro.

Importa destacar que a pesquisa se iniciou de maneira espontânea no Google (www.google.com). Este site direcionava, primordialmente, para endereços situados à Avenida Neli Sobreira, nomeada assim em homenagem à professora objeto deste estudo, não aparecendo, no entanto, nenhum texto científico relacionado ao seu nome. A busca pela produção acadêmica sobre "Neli Sobreira" deu-se no banco de teses e dissertações da Coordenadoria de Aperfeiçoamento de Pessoal de Nível Superior (Capes), onde não se encontrou nada com esse descritor no campo "assunto". Fato idêntico ocorreu na busca realizada no Scientific Electronic Library Online (SciELO). Já no portal de periódicos da Capes, no campo "buscar assunto", localizaram-se três registros, mas esses faziam referência ao sobrenome "Sobreira", autor da área da saúde. A homenagem a Neli Sobreira como nome para um logradouro gerou uma dualidade instigante: o tempo que a sociedade "imortaliza" a educadora, condecorando-a em placa de denominação de via de circulação pública, quando paradoxalmente não há qualquer estudo que possibilite preservar sua história e memória, ainda que seu nome seja amplamente conhecido em Juazeiro do Norte.

Ante a ausência de pesquisas e a representatividade social de Neli Sobreira, salienta-se a relevância de elaborar sua biografia hermeneuticamente para constituição e preservação da história da educação local. Pois ao lançar luz às suas contribuições educacionais e sociais e disseminar sua história de vida na interface com o contexto sócio-histórico por meio deste artigo, fomenta-se fonte para o estudo da história educacional do Cariri enquanto se ampliam possibilidades de compreensão do cenário historiográfico do Ceará.

Defende-se o argumento de que Neli Sobreira foi uma freira que não atuou apenas no campo religioso de Juazeiro. Ao contrário, foi mulher pioneira na política, elegendo-se vereadora, e na atuação educacional com habilitação específica, além de muito atuante na área da assistência social, galgando importante papel na educação de crianças e na luta pela garantia de direitos à população pobre do Cariri entre 1946 e 2017. 


\section{Gênero biográfico na História da Educação: o percurso metodológico}

Considerando que propomos, por meio da pesquisa, desenvolver uma biografia, inserida no campo da História da Educação, referente à educadora Neli Sobreira e com ênfase na sua atuação profissional no campo da Educação e Assistência Social, faz-se necessário esclarecer o conceito de biografia utilizado. Tal gênero de historiar aqui concebido, ao contrário de consagrar "grandes vultos" - outrora analisados e interpretados pelos metódicos da escola positivista "rankeana" oitocentista, em uma história personalista; centrada na figura de heróis, mártires, gênios, sábios e santos, que afastou os historiadores dos estudos biográficos por muito tempo (RODRIGUES, 2015) - lança novos olhares, na perspectiva micro-histórica (LORIGA, 2011). Por meio desta perspectiva, é possível ensejar luz às particularidades da vida na interface com o contexto sócio, histórico e cultural de maneira crítica, sem necessidade de cronologia (LE GOFF, 2008), com sentido metonímico, buscando conhecer o coletivo pelo individual, o todo pelas partes, onde "o todo é a sociedade da época vivida pelo personagem central e pelos sujeitos que com ele formaram a urdidura apresentada pelo narrador, na qual se deu a interatividade entre o personagem e o ambiente físico e social.” (RODRIGUES, 2015, p. 57).

Comunga-se com Nunes (2008) ao compreender que a biografia de educadoras permite analisar hermeneuticamente a diversidade de professoras em suas particularidades, considerando a história das práticas e as representações educativas que fomentam a trajetória docente de maneira contextualizada, inclusive possibilitando alargar a compreensão de aspectos culturais e sociais que perpassam o imbricamento entre a vida individual e coletiva. A biografia de Neli Sobreira, por sua vez, desenvolvida por intermédio de fontes orais e escritas, possibilitou indução de pertinentes análises historiográficas dos acontecimentos individuais das várias fases da vida de uma professora, nas sobreposições com o coletivo, reverberando relevo na preservação da memória social (BORGES, 2008).

Esta biografia, ao preocupar-se em evidenciar a vida de Neli Sobreira, utilizou a metodologia da história oral híbrida defendida por Meihye Holanda (2007), ou seja, as oralidades foram tomadas como fonte principal e complementadas com outras escritas e fontes documentais. As fontes orais utilizadas foram coletadas por meio de entrevistas abertas gravadas, transcritas, textualizadas e validadas (MEIHY; RIBEIRO, 2011) sobre a vida de Neli Sobreira, em especial no que concerne à sua educação e atuação profissional.

A pesquisa contou com quatro participantes: Neli Sobreira, a biografada (2005, 2007, 2015, 2017); Professora Maria Guiomar Filgueira Calou (2015), 
companheira de trabalho de Sobreira por mais de 50 anos; Professor Renato Dantas (2017), historiador local; e Raimundo Araújo (2015), memorialista.

A principal colaboradora foi a própria Neli Sobreira - mulher idosa, que completou 92 anos em 2017 - que intercalava momentos de plena lucidez (com memórias ricas em detalhes verbalizados) com instantes de esquecimento. Suas entrevistas foram coletadas em quatro encontros de aproximadamente 40 minutos cada, respeitando sua desenvoltura limitada pelo breve cansaço oriundo da idade avançada como nos sugere Bosi (1987). Os outros entrevistados foram importantes para confirmar datas e dados esquecidos por Sobreira, complementando e acrescentando informações pertinentes acerca da atuação profissional da biografada.

As lembranças, recordações e esquecimentos compõem o substrato da pesquisa em história oral (ALBERTI, 2006), principalmente com idosos. Delgado (2010, p. 16) acrescenta:

A memória, principal fonte dos depoimentos orais, é um cabedal infinito, onde múltiplas variáveis - temporais, topográficas, individuais, coletivas - dialogam entre si, muitas vezes revelando lembranças, algumas vezes de forma explícita, outras vezes de forma velada, chegando em alguns casos a ocultá-las, pela camada protetora que o próprio ser cria ao supor, inconscientemente, que assim está se protegendo das dores, dos traumas e das emoções que marcam sua vida.

Sem ignorar os percalços da lembrança e do esquecimento ocasionados propositalmente ou não pela memória dos entrevistados (NORA, 1993), concebe-se a oralidade como fonte oportuna para esta pesquisa, tanto pelo valor das narrativas quanto pela ausência de fontes documentais que pudessem propiciar a narrativa histórica proposta. Importou considerar a ata da Reunião de Criação do Dispensário Nossa Senhora das Dores como fonte complementar. Mesmo que esta não diga respeito à vida de Neli Sobreira, todavia permitiu situar temporal e espacialmente a chegada da Congregação das Missionárias de Jesus Crucificado em Juazeiro, da qual ela decidiu participar. Importa esclarecer que as "[...] fontes não supriram por completo a biografia [...], nem esvaziaram as possibilidades de emergência de novos dados" (ALMEIDA, 2017, p. 339), mas os documentos encontrados foram considerados relevantes para amparar a narrativa biográfica em tela.

O método biográfico utilizado endossou a compreensão de que o indivíduo e a sociedade são esferas inseparáveis da narrativa histórica (FERREIRA; 
AMADO, 2006), pois entendeu a realidade como um “[...] conjunto mutável de interdependência entre os indivíduos na totalidade das suas ações e múltiplas experiências de vida, em suas intricadas relações sociais." (MACHADO, 2010, p. 115). Concorda-se com Levi (1996), ao entender a biografia como um espaço, um lugar de tomada de decisões no qual transpiram tensões entre a racionalidade dos sistemas sociais e de emancipação dos indivíduos. Com efeito, a biografia de Neli Sobreira não objetiva macular imagem, mas procura nas partes a presença do todo ao permitir articular o individual ao social, o micro ao macro (LORIGA, 2011), ampliando as compreensões no campo da História da Educação.

A narrativa biográfica de Neli Sobreira reconstitui sua história desde o seu nascimento, perpassando por seus percursos de formação (na educação primária, secundária e no curso de aperfeiçoamento), mas, principalmente, lança luz para a sua atuação profissional e contribuições no campo educacional e social.

\section{Irmã Neli Sobreira: religião, educação e política}

Maria Neli Sobreira da Silveira, conhecida como Irmã Neli, nasceu em 14 de agosto de 1925, na Cidade de Juazeiro do Norte, Ceará, na localidade chamada Sítio Brejo Seco, também conhecido como Sítio Queimado, no bairro Timbaúbas. Filha de João Alexandre Sobreira da Silveira e Cecília Gonçalves Sobreira, agricultores, com família relativamente numerosa (quatro filhos e duas filhas), ela sempre teve o apoio dos genitores para estudar, pois se preocupavam com a formação educacional dos filhos a fim de que os descendentes tivessem um futuro melhor (DANTAS, 2017).

Em Brejo Santo viveu sua primeira experiência escolar com uma professora leiga que lhe dava aulas particulares. Sobreira relembrou a sua primeira professora, Carolina Moreira Dias, explicitando que "com Carolina terminei a carta do $A B C^{4}$ e passei a estudar no Grupo Escolar Padre Cícero até o $5^{\circ}$ ano (1940), atualmente chamado de Escola de Educação Infantil e Fundamental Padre Cícero" ${ }^{5 "}$. Esse Grupo foi fundado com

4 A carta do $\mathrm{ABC}$ era uma espécie de cartilha, ou seja, de um livro didático elaborado para a alfabetização de crianças, amparando o trabalho pedagógico das professoras no ensino da escrita da leitura.

5 O Grupo Escolar foi fundado em 18 de setembro de 1927, pelo Dr. Juvêncio Santana. Em 1935, foi construído e inaugurado o atual prédio da Escola de Educação Infantil e Fundamental Padre Cícero, situada no bairro Socorro, Centro de Juazeiro do Norte. 
[...] a chegada ao Crato, em 1864, do Padre Ibiapina, que realizou obras caritativas nos setores social e educacional, culminando com a criação do Seminário São José, em 1875. Este era orientado pelos Padres Lazaristas, que difundiam a filosofia cristã através da formação de quadros para a Igreja e através dos seus colégios de $1^{\circ}$ e $2^{\circ}$ Graus para formar a elite intelectual para a região. (QUEIROZ, 2008, p. 21).

O ensino primário de Neli Sobreira foi pautado nos ideários do catolicismo, fomentado na filosofia cristã, assumido por eclesiásticos que lecionavam e dirigiam o Grupo Escolar Padre Cícero com vistas a formar crianças e jovens da localidade. Dando continuidade aos seus estudos, passou a frequentar a Escola Normal Rural de Juazeiro do Norte ${ }^{6}$, concluindo o ginásio (1944) e o $3^{\circ}$ normal, com o pedagógico, qualificando-se como professora ao receber o diploma em 10 de dezembro de 1946 . Em $1^{\circ}$ de janeiro do ano seguinte, foi convidada por D. Amália Xavier de Oliveira ${ }^{7}$, diretora da instituição, para fazer parte do quadro de professores da referida Escola Normal, lecionando português e matemática. Tempos depois seguiu para Recife para fazer parte do Curso de Aperfeiçoamento de Ensino Secundário (CADES), uma espécie de graduação equiparada ao nível superior, permanecendo ali por três anos, já que o Crato carecia dessa formação complementar. Voltou de Recife por conta do adoecimento de seu pai, que necessitava de cuidados especiais.

Ao retornar a Juazeiro do Norte para continuar lecionando na Escola Normal, assumiu também uma cadeira na Escola Técnica do Comércio de Juazeiro do Norte, lócus este que fomentou sua inserção na vida pública e política com o escopo de lutar por melhorias para Juazeiro e para os trabalhadores e demais moradores menos privilegiados economicamente. Tal envolvimento gerou engajamento comunitário e apoio social, o que ampliou sua visibilidade e respaldou seu lastro para atuação efetiva na política. Seu pai estimulou-a, com ênfase, para que utilizasse seu prestígio social para se candidatar a vereadora - o que fez em 1947, sendo eleita, para o triênio 1948-1950, com apenas 23 anos.

Em entrevista, Sobreira relembra: "não cheguei a concluir meu mandato, pois essa não era a minha vontade e sim de meu pai"; e acrescenta:

Em 1943, aos 18 anos, fui candidata pelo PSD e eleita a primeira vereadora mulher de Juazeiro. Na época o prefeito eleito era do

6 Primeira Escola Normal Rural do Brasil, fundada em 1934.

7 Dona Amália Xavier de Oliveira foi educadora em Juazeiro do Norte, tendo sido responsável pela fundação da Escola Normal Rural de Juazeiro do Norte, no ano de 1934, sendo conhecida na História da Educação Brasileira como a primeira escola normal rural do Brasil. 
mesmo partido, era José Monteiro de Macedo. Minha atuação na câmara se deu por apenas 02 anos, pois, em 1948, por convite de Amália Xavier, comecei a lecionar na Escola Normal Rural no segundo ano primário e larguei o cargo de vereadora. (SILVEIRA, 2005).

É mister clarificar que Sobreira tornou-se vereadora com 23 anos, a idade de 18 anos proferida por ela na narrativa foi uma incongruência decorrente do esquecimento provocado pela perda de memória oriunda da idade avançada. O pioneirismo feminino de Sobreira na política local, no entanto, é conferido pelo fato de ser a primeira mulher da região a assumir um cargo político, ainda que este não lhe trouxesse encantamento. Nesse mesmo período, ela percebeu a preponderância da sua inclinação para a vida religiosa e missionária, congruente com a formação recebida no Grupo Escolar e na Escola Normal. Foi então que em $1^{\circ}$ de julho de 1948, quando da inauguração do Dispensário Nossa Senhora das Dores de Juazeiro, apresentou-se como candidata à Congregação dos Missionários de Jesus Crucificado.

De acordo com a Ata de criação da instituição no $1^{\circ}$ de julho de 1948 , foi fundado o Dispensário Nossa Senhora das Dores, trazendo do Sul do país as missionárias de Jesus Crucificado. Naquela ocasião, fizeram parte da fundação a Madre Geral da Congregação, Maria do Calvário, sua secretária, Madre Verônica Martins, e outras irmãs e autoridades locais. De acordo com a referida Ata (1948, não p.): "a finalidade desta obra seria beneficiar os pobres, para quem a casa foi fundada".

Em 10 de janeiro de 1949, após um ano de funcionamento da instituição, Sobreira ingressou definitivamente na vida religiosa. Ela abandonou a vida pública na política e tornou-se noviça, mantendo-se professora. Na ocasião, iniciou o trabalho educacional e missionário na comunidade do Sítio Limoeiro, atualmente conhecido como bairro Limoeiro, situado na área periférica do centro da cidade de Juazeiro do Norte, com maior concentração de pobreza.

Após anos de docência e trabalhos voluntários de assistencial social, segura em sua decisão de devoção a Deus, sob os princípios doutrinários da Igreja Católica, passou uma temporada em São Paulo para ser consagrada freira em 1956, depois de ter proferido seus votos perpétuos. Irmã Neli, como ficou conhecida após o uso do hábito, passou a ser diretora do Convento das Irmãs.

Em 1960, ao retornar a Juazeiro do Norte, recebeu o cargo de $3^{\circ}$ Superiora da Congregação e foi lecionar na Escola Monsenhor Macedo. Em 1968, tornou-se a primeira diretora do Colégio Felipe Néri, uma instituição municipal da cidade, 
a convite do prefeito da época. Em 1972, por indicação do governador do Estado, retornou como professora para a Escola Normal Rural com 47 anos, lecionando no ensino científico, instituição na qual obteve a sua aposentadoria como professora.

Muito comunicativa, com boa oralidade, bem relacionada e contundente em seus argumentos, utilizou seus atributos também para dinamizar as pastorais, por exemplo, com a criação da famosa Festa do Padroeiro São José. Ela conseguia agregar, com alegria, fiéis e colaboradores. Participou da fundação do Centro de Evangelização, de uma Casa Paroquial e do Centro Social Madre Maria Vilac. Neste último, irmã Neli desenvolveu a maior parte da sua atividade educativo-social.

A entrevistada contou que no sítio Limoeiro, zona rural da cidade, grande parte das terras pertenciam à Congregação das Missionárias de Jesus Crucificado, e ela conseguiu que fosse doado um terreno, em 1970, para a construção do mencionado Centro Social que beneficiaria as famílias carentes daquela comunidade, transferindo sua sede para o centro de Juazeiro, antes localizada à Rua São José. Foi neste espaço, construído sob sua coordenação por intermédio de donativos e mutirão de trabalho, concluído em 1972, que ela ampliou os serviços ofertados pelo Dispensário Nossa Senhora das Dores ${ }^{8}$.

Nos registros consta que a primeira ação da instituição foi a educação escolar. Na ocasião foram "levantadas as paredes e cobertas duas salas, iniciando as atividades de alfabetização, com duas professoras, Irmã Alzira e Maria Guiomar, e sessenta crianças carentes" (ARAÚJO, 2015). Lembra o memorialista que "em condições precárias, as crianças sentavam-se em esteiras colocadas sobre o chão de barro batido e as refeições servidas eram obtidas através de doações, assim como o material utilizado.”. (ARAÚJO, 2015).

Sendo uma entidade filantrópica e mantida por donativos, o Dispensário passou por momentos muito difíceis: as irmãs, sob o comando de Neli Sobreira, não se cansaram de bater nas portas das autoridades, de lojistas e da sociedade em geral para pedir doações. Frequentaram as rádios locais divulgando o trabalho e pedindo colaborações, obtendo ajuda constantemente, como a mesma relata: "Nunca me disseram: 'não'. Toda ajuda era bem-vinda, fosse de material de construção, alimentos, móveis, roupas, remédios, tudo que trouxesse benefícios para a comunidade." (SILVEIRA, 2007). Na ocasião, Gilberto Sobreira, comerciante e irmão de Sobreira, doou todo o material para a construção de um pavilhão de salas de aula e um refeitório.

O Centro Social foi sendo ampliado e começou a ter ações que beneficiavam não só as crianças, mas também às famílias carentes. Em 1973, foi iniciado o trabalho socioeducacional no Centro Social, sendo reconhecido em 15 de agosto

8 O Dispensário funcionou inicialmente na Rua São José, mas em 1972 foi transferido para o Sítio Limoeiro, tendo a Madre Neli se prontificado a ser sua diretora. 
de 1975. Com o passar do tempo, o Centro Social passou a acolher a comunidade em geral, recebendo ajuda do município e do Estado, pois desenvolvia muitos trabalhos de ação social e possuía as credenciais necessárias para ser considerada instituição filantrópica. Em 23 de setembro de 1976, a escola recebeu a visita da Legião Brasileira de Assistência (LBA), que firmou convênio de parceria para ação junto às crianças, fomentando apoio financeiro para o incremento das ações de assistência e educação. De acordo com a Irmã Neli, foi "uma das melhores épocas do Centro Social" (SILVEIRA, 2007).

$\mathrm{Na}$ ocasião, as atividades executadas eram: assistência ao menor (criança na faixa etária de 2 a 6 anos com escolarização pré-escolar); atendimento às famílias carentes, residentes na comunidade, com aporte de recursos para necessidades básicas através de atividades comunitárias de doação; realização de cursos profissionalizantes (pedreiro, corte e costura, modelagem, artesanato em palha, datilografia, eletricista etc.); desenvolvimento do Projeto Casulo, com a construção do berçário no qual ficavam as crianças cujos pais precisavam trabalhar e não tinham com quem deixar seus filhos, provendo-os com alimentação e ensino; acompanhamento às grávidas mediante formação do Clube das Mães Gestantes; articulação e acompanhamento de adolescentes por meio da criação do Clube de Jovens, também denominado de Projeto Elo, que desenvolvia ações de empoderamento e acompanhamento educacional; fornecimento de alimentação para seiscentas crianças carentes; cultivo de horta comunitária, que ajudava no incremento à alimentação com menor custo; instituição de uma enfermaria para atendimento à comunidade, inclusive, com atendimento médico e odontológico gratuito; apoio à legalização da situação documental das famílias; criação de uma agência de empregos que cadastrava os desempregados para articular uma colocação profissional; e o desenvolvimento de ações religiosas de catequese de jovens e adultos, congruente com os princípios católicos de sua formação.

Dentre os inúmeros serviços prestados à comunidade, importa destacar ainda mais duas ações: apoio às mães que não podiam ou não queriam cuidar de seus filhos, entregando-os ao centro para adoção, que registrou: "mais de 80 crianças foram entregues a famílias interessadas" (SILVEIRA, 2007); e o projeto na área de habitação, que doou casa própria, com a construção da Vila Monsenhor Macedo, para assegurar moradia digna às famílias carentes do dispensário.

Em 1994, o convênio com a LBA encerrou-se, levando a instituição a passar por momentos difíceis. Lembra a Irmã Neli: "havia noites em que eu parava para pensar: como vai ser amanhã? Mas, em nenhum momento pensei em desistir, sempre busquei ajuda e donativos e cada conquista era motivo de alegria e festa" (SILVEIRA, 2007).

Irmã Neli, com vista a minimizar a escassez de recursos, programou o Projeto Tilápia, com a construção de cinco tanques para serem utilizados na 
criação desse tipo de peixe, inspirado em ação inovadora desenvolvida na África e incentivada pela Irmã Aneti, colega de congregação, que conheceu tal projeto na sua visita ao referido continente. O projeto resultou em mais alimentação, sendo os peixes destinados a mitigar a fome das crianças atendidas; além de produzir material rico em vitaminas, com forte poder nutritivo, a ser consumido.

Os serviços rotineiros de cuidados com o centro foram desenvolvidos, principalmente, por dez famílias que lá moravam. Elas não pagavam aluguel e recebiam alimentação; em troca, comprometiam-se a colaborar com os projetos e os serviços de assistência e manutenção do prédio.

O centro mudou de nome quatro vezes: inicialmente chamado de Centro Social do Dispensário Nossa Senhora das Dores, posteriormente, de Escola de $1^{\circ}$ Grau do Dispensário Nossa Senhora das Dores, ocasião em que implantou a $1^{a}$ série. Em seguida, denominou-se Escola Municipal de Educação Infantil do Dispensário Nossa Senhora das Dores, deixando de ofertar a primeira série do ensino fundamental; e, por fim, Escola Municipal de Educação Infantil Monsenhor Macedo ${ }^{9}$, após administração assumida pela gestão municipal de Juazeiro.

Desde a fundação até 2015, a direção ficou a cargo da Irmã Neli Sobreira, "Diretora vitalícia", com 35 anos de direção e 57 anos de Congregação. Ao seu lado, desde o início, Sobreira contou com o apoio da amiga Maria Guiomar Filgueiras Calou, primeira professora do centro que, mesmo aposentada, ainda trabalhava como voluntária na função de tesoureira. Em entrevista com a mais antiga parceira de Sobreira, ela relata que toda a história do Centro Social do Dispensário Nossa Senhora das Dores foi marcada por grandes lutas e conquistas:

Atualmente, depois de muita luta, a escola foi municipalizada, funcionando com a Educação Infantil do Maternal ao Jardim II, com uma média de trezentos alunos matriculados, funcionando os dois horários, com 8 salas pela manhã e 6 à tarde, totalizando 14 salas de aulas, uma diretoria, uma secretaria, sala de informática, biblioteca infantil, biblioteca comunitária, brinquedoteca, almoxarifado, enfermaria, cozinha/refeitório, bebedouros, banheiros infantis (masculino e feminino), banheiro para funcionários e professores, bica de lazer, auditório e áreas de lazer (CALOU, 2015).

Completados os seus 90 anos, em 2015, mesmo aposentada, ainda mantinha seus projetos educacionais de apoio às mães da localidade e o trabalho de

9 O nome Monsenhor Macedo foi uma homenagem ao diretor espiritual que muito se dedicou à Congregação das Missionárias de Jesus Crucificado. 
orientação pedagógica às professoras do bairro Limoeiro e circunvizinhança. Mas a gestão da escola já lhe custava recursos e esforços, por isso a sua municipalização foi considerada a melhor opção para amparar, com a devida qualidade, as crianças da educação infantil, tanto da creche como da pré-escola, ainda que continuasse apoiando-a, como exemplifica:

Eu vou fazer 90 anos, esse ano, nós fizemos um projeto: Projeto 90. Que é a instalação de quinze berçários. Estão lá, é bom fazer uma visita, é a coisa mais linda do mundo, com alimentação da manhã, alimentação da tarde e só saem depois que tomam a sopa da tarde e saem com as mães. Nós fundamos, não fui só eu não, foi eu e minhas companheiras. Agora, essas crianças são filhos das mães que trabalham no comércio, nas casas de família e deixam as crianças o dia todo conosco, às 17 h as crianças saem e encerra o expediente (SILVEIRA, 2015).

Sobreira, impossibilitada de se locomover e com restrições de saúde, não prescindia da sua atuação no campo educacional:

Hoje sou aposentada, mas não terminei de trabalhar [...] comprei a escola. Adoeci após três quedas que maltratou a espinha, estou na cadeira de roda. Daqui da cama eu fico orientando, vou lá, me levam na cadeira de roda, lá eu desço e vejo as crianças, mas volto. E aqui eu continuo a vida de professora, velha e aposentada (SILVEIRA, 2015).

Após dois anos do referido depoimento, com 92 anos, irmã Neli precisou se afastar da escola. Com a saúde debilitada, vive no Centro de Evangelização que fundou; e narra:

Estou terminando aqui na cadeira de roda, mas estou aqui ainda na ativa e a cabeça está boa, só a garganta que está ruim e as pernas não dão pra gente andar. Foi essa minha vida de professora, nos dias de hoje estou aposentada, aqui nesse centro, essa casa aqui que fundei quando tinha saúde, agora eu estou só assim recebendo as visitas e as entrevistas, mas bem. (SILVEIRA, 2017). 
Ante tanta participação nas diversas instituições educacionais do Juazeiro, algumas na condição de professora, outras como diretora e outras como fundadora, Irmã Neli foi lembrada na comemoração dos seus 92 anos, sendo assim retratada:

Criada dentro de uma vida religiosa católica, o seu destino estava traçado para o serviço ao próximo e a Deus. A sua missão começou a ter seus primeiros contornos com a Fundação das Missionárias de Jesus Crucificado em 01 de julho de 1948, quando a Irmã Neli expressou para a Madre Geral a vontade de ser religiosa, postulando-se a noviça em 10 de janeiro de 1949 e fazendo os votos perpétuos em 26 de fevereiro de 1956, consagrando-se definitivamente na Congregação. Quem no bairro Limoeiro não conhece a Irmã? Que muito contribuiu para o crescimento desta comunidade, se tornando grande, por muito esforço da religiosa, que continua sua missão até os dias atuais, cuidando dos seus irmãos. Ali em $1^{\circ}$ de julho de 1948, com 24 anos, sentiu o chamado para a vida religiosa, através da Fundação da primeira casa missionária em Juazeiro e que recebeu o nome de Dispensário Nossa Senhora das Dores. (MARQUES, 1988 , não p.).

Sua trajetória como educadora e missionária se fundiu com o crescimento da Irmandade de Jesus Crucificado e da obra educacional e assistencial do Dispensário Nossa Senhora das Dores, que ainda mantém atividades dessa natureza. Tal é o reconhecimento do seu trabalho junto às pessoas menos abastadas, em prol de ajudar a educar, garantir direitos e lutar por melhores condições de vida, que o memorialista Raimundo Araújo, na comemoração dos 90 anos de irmã Neli, explicita:

Ela é uma das estrelas da constelação juazeirense. E um astro humano em movimento no tempo e no espaço. Por isso é merecedora nesta data em que comemora seus 90 anos de existência das mais justas homenagens de Juazeiro pelo seu edificante e abnegado trabalho em prol das famílias carentes do Bairro do Limoeiro. (ARAÚJO, 2015).

Importou, pois, biografar Irmã Neli Sobreira e preservar a memória e a história dessa mulher que não recebeu a devida visibilidade na historiografia oficial, já que nada há publicado nas bases de dados científicas. No entanto, ela 
contribuiu sobremaneira para a História da Educação e da assistência social aos pauperizados de Juazeiro, ao laborar como professora, gestora, vereadora e fundadora de instituições visando a melhoria do cenário educacional e social da região do Cariri.

\section{Considerações finais}

Por meio do estudo, investigou-se que formação educacional e atuação profissional foram desenvolvidas por Neli Sobreira para que esta madre educadora se constituísse figura relevante na memória coletiva local, desde a alfabetização de crianças à assistência social prestada às famílias na cidade de Juazeiro do Norte, Ceará (1946-2017). Para desvelar o escopo de compreender a formação educativa ensejada à Neli Sobreira e, especialmente, sua atuação profissional na interface com o contexto sócio-histórico da cidade de Juazeiro, desenvolveu-se uma pesquisa qualitativa. A pesquisa foi amparada metodologicamente pela história oral, do tipo biográfica, que reconstituiu a vida de Sobreira com amparo nas suas narrativas, nas de sua parceira de trabalho, nas de um historiador e de um memorialista local, coletadas por meio de entrevistas.

Os resultados permitiram inferir que Neli Sobreira foi uma freira que não atuou apenas no campo religioso de Juazeiro, mas também desenvolveu atividades de professora, na condição de primeira normalista com curso de aperfeiçoamento equiparado ao ensino superior. Ela atuou na Escola Normal Rural de Juazeiro do Norte, na Escola Técnica do Comércio de Juazeiro do Norte e na Escola Monsenhor Macedo e como gestora de escola (Colégio Felipe Néri) e de instituições assistenciais (Convento das Irmãs, Dispensário Nossa Senhora das Dores). Também foi membro fundadora de diversas instituições (Centro de Evangelização, Casa Paroquial, Centro Social Madre Maria Vilac) e coordenadora de diversos projetos assistenciais (Projeto Casulo, Clube das Mães Gestantes; Clube de Jovens, Projeto Elo, Projeto Habitacional, Peixe Tilápia etc.). Além disso foi vereadora, galgando pioneirismo feminino nos bancos da Câmara Municipal de Juazeiro do Norte.

Sua trajetória no campo educacional e assistencial, na luta pela garantia de direitos à população pobre no Cariri, não lhe rendeu qualquer remuneração ou patrimônio tampouco visibilidade no cenário historiográfico. No entanto, foi importante para fomentar escolarização às crianças, possibilitar trabalho aos pais e assistir às necessidades básicas de alimentação e moradia à população carente, dentre outras benfeitorias realizadas mediante seus projetos com 
foco em proporcionar melhores condições de vida à população pauperizada do Juazeiro do Norte.

Esse estudo possibilitou, em suma, por intermédio da trajetória de vida de uma freira-professora, registrar e preservar a história de uma professora cearense que tanto contribuiu para o desenvolvimento do contexto educacional do estado e, com efeito, ficou relegada aos porões do olvido. E, ainda que limitada pela impossibilidade de generalização, a pesquisa biográfica lança luz à compreensão da participação feminina na História da Educação no Ceará.

\section{REFERÊNCIAS}

ALBERTI, V. História dentro da história. In: PINSKY, C. B. (Org.). Fontes históricas. 2. ed. São Paulo: Contexto, 2006.

ALMEIDA, W. R. A. de. Professor Leovegildo Chagas Santos (1955): patrono do terceiro grupo escolar de Limeira, estado de São Paulo. História da Educação, Porto Alegre, v. 21, n. 52, p. 335-355, 2017.

ARAÚJO, R. Irmã Neli: 90 anos. Portal do Juazeiro, on-line, 14 ago. 2015. Disponível em: <http://www.portaldejuazeiro.com/2015/08/maria-nely-sobreira-da-silveira-irma. html>. Acesso em: 20 ago. 2015.

BORGES, V. P. Grandezas e misérias da biografia. In: PINSKY, C. B. (Org.). Fontes históricas. 2. ed. São Paulo: Contexto, 2008, p. 203-223.

BOSI, E. Memória e Sociedade: lembrança de velhos. 2. ed. São Paulo: EDUSP, 1987.

DELGADO, L. A. M. História Oral: memória, tempo e identidade. Belo Horizonte: Autêntica Editora, 2010.

DELLA CAVA, R. O milagre de Juazeiro. São Paulo: Editora Cortez, 2014.

FERREIRA, M.; AMADO, J. Usos \& Abusos da história oral. 8. ed. Rio de Janeiro: Editora FGV, 2006.

GOIANA, I. S. A memória histórica educativa do Orfanato Jesus Maria José na cidade de Juazeiro do Norte: 100 anos de permanências e rupturas (1916 a 2016). 2016. Dissertação (Mestrado em Educação Brasileira) - Universidade Federal do Ceará, Fortaleza, 2016.

LE GOFF, J. História e Memória. Campinas: Editora da Unicamp, 2008.

LEVI, G. Usos da biografia. In: AMADO, J.; FERREIRA, M. de M. (Org.). Usos \& abusos da história oral. Rio de Janeiro: FGV, 1996. p. 167-182.

LORIGA, S. O pequeno $x$ : da biografia à história. Belo Horizonte: Autêntica, 2011. 
MACHADO, C. J. dos S. Zilda da Costa Mamede (1928-1985): passos de uma pesquisa biográfica. In: VASCONCELOS, J. G. (Org.). Tempo, espaço e memória da educação: pressupostos teóricos, metodológicos e seus objetos de estudo. Fortaleza: UFC, 2010. p. 114-126.

MADEIRA, M. das G. de L. A Pedagogia das Casas de Caridade do Padre Ibiapina. Fortaleza: UFC, 2008.

MARQUES, D. W. A. O pensamento vivo de Padre Cícero. São Paulo: Martin Claret, 1988.

MEIHY, J. C. S. B.; RIBEIRO, S. L. S. Guia prático da história oral. São Paulo: Contexto, 2011.

MEIHY, J. C. S. B.; HOLANDA, F. História oral: como fazer, como pensar. São Paulo: Contexto, 2007.

NORA, P. Entre memória e história: a problemática dos lugares. Traduzido por Yara Aun Khoury. Projeto História, São Paulo, PUC-SP, n. 10, p. 12, 1993.

NUNES, M. L. da S. Uma página feminina: vozes de mulheres paraibanas na década de 1930. In: CONGRESSO BRASILEIRO DE HISTÓRIA DA EDUCAÇÃO: O ENSINO E A PESQUISA EM HISTÓRIA DA EDUCAÇÃO, 5., 2008, Aracaju/SE. Anais... Disponível em: <http://www.sbhe.org.br/novo/congressos/cbhe5/pdf/580.pdf>. Acesso em: 12 jan. 2014.

QUEIROZ,Z. F. de. Em cada sala um rosário, em cada quintal uma oficina: o tradicional e o novo no ensino tecnológico no cariri cearense. Fortaleza: UFC, 2008.

RODRIGUES, R. M. Biografia e gênero. In: FIALHO, L. M. F. et al. (Org.). Biografia de mulheres. Fortaleza: EdUECE, 2015.

\section{Documento}

ATA. Reunião de Criação do Dispensário Nossa Senhora das Dores, Juazeiro do Norte, 1972.

\section{Entrevistas}

ARAÚJO, Raimundo. Entrevistador: Daniel Walker Almeida Marques. Juazeiro do Norte, abr. 2015.

CALOU, Maria Guiomar Filgueira. Entrevistadora: Zuleide Queiroz. Juazeiro do Norte, mar. 2015.

DANTAS, Renato. Entrevistadora: Zuleide Queiroz. Juazeiro do Norte, dez. 2017.

SILVEIRA, Madre Neli Sobreira da. Entrevistadora: Zuleide Queiroz. Juazeiro do Norte, maio 2005 . 
SILVEIRA, Madre Neli Sobreira da. Entrevistadora: Zuleide Queiroz. Juazeiro do Norte, mar. 2007.

SILVEIRA, Madre Neli Sobreira da. Entrevistadora: Zuleide Queiroz. Juazeiro do Norte, mar. 2015.

SILVEIRA, Madre Neli Sobreira da. Entrevistadora: Zuleide Queiroz. Juazeiro do Norte, dez. 2017.

Texto recebido em 27 de março de 2018.

Texto aprovado em 18 de maio de 2018. 